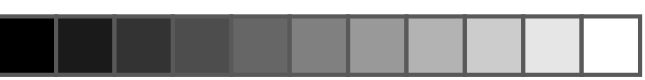

\title{
MOBILIZAÇÃO DE COMUNIDADES QUILOMBOLAS E A INTERFACE COM AS INSTITUIÇÕES PÚBLICAS: A ACONERUQ E O MOQUIBOM NO MARANHÃO
}

Igor Thiago Silva de Sousa ${ }^{1}$

Clarianne Natali de Campos $^{2}$

\section{RESUMO}

Este trabalho tem como objetivo analisar os processos de mobilização das comunidades quilombolas no Maranhão, a partir das ações do Movimento Negro, através do CCN-MA (Centro de Cultura Negra do Maranhão), e sua interferência direta na garantia de direitos territoriais às chamadas "comunidades remanescentes de quilombos" em âmbito regional, por meio de projetos de mapeamento e registro de conflitos agrários, bem como o registro do surgimento segmentos organizados específicos destas comunidades, a saber, a ACONERUQ (Associação de Comunidades Negras Rurais Quilombolas) e o MOQUIBOM (Movimento Quilombola do Maranhão), chamando atenção para as estratégias de ação, leituras políticas e processos organizativos

1 Cursa Doutorado em Sociologia pela Universidade Federal do Rio Grande do Sul (UFRGS). Professor da Licenciatura Intercultural para Educação Básica Indígena/UEMA (Universidade Estadual do Maranhão).

2 Bacharela em Direito pela Universidade Federal do Maranhão (UFMA). Professora da Universidade Ceuma. 
multifacetados em torno do acionar dos direitos assegurados formalmente e interfaces frente a instituições estatais.

Palavras-Chave: comunidades quilombolas; mobilização; ACONERUQ; MOQUIBOM.

\section{A CONSTITUIÇÃO DE 1988 E O DIREITO TERRITORIAL DOS REMANESCENTES DE QUILOMBOS}

A Constituição brasileira de 1988, muito mais que um marco jurídico, é reflexo de um momento histórico, sendo a consolidação da expressão dos mais conflituosos anseios de reforma social, produto de uma demorada luta pela redemocratização do país. Evento com grande carga simbólica, o momento constituinte representou a tentativa de um acerto de contas do Estado para com a sociedade, em especial, com os grupos desprivilegiados da história nacional, como indígenas e comunidades quilombolas, por exemplo. Devido a sua ênfase abarcadora de distintas realidades e necessidades, costuma afirmar-se que esta Carta Magna possui caráter pluricultural (BRITTO, 2003; FERREIRA, 2010).

A Constituição de 1988, neste espírito, juridicizou um ambicioso projeto de reforma social. Lançou mão de um conhecido mecanismo do estado de bem-estar que se multiplicou na segunda metade do séc. XX: o amplo reconhecimento de direitos, somando às liberdades individuais os direitos sociais $\mathrm{e}$ coletivos. Aos juristas habituados ao raciocínio jurídico tradicional, impôs-se a obrigação de construir técnicas diferentes de interpretação. Atribuiu-se nova função ao direito em geral, e ao direito constitucional em particular. Ao lado de disciplinar e estabilizar as relações sociais, caberia ao direito também transformá-las segundo os princípios de justiça inscritos na norma constitucional. Esta função transformadora teria como agente central o Estado, obrigado a se reinventar para cumprir suas novas metas (SUNFELD et al., 2002). 
Como mencionado, um dos grupos-alvo da nova Constituição foram as comunidades quilombolas, as quais foram contempladas em alguns dispositivos do novo texto, em especial, no art. 68 do Ato das Disposições Constitucionais Transitórias (ADCT), garantindo a propriedade àqueles que o legislador se referiu por remanescentes das comunidades de quilombo. De acordo com o citado: Artigo 68, "aos remanescentes das comunidades dos quilombos que estejam ocupando suas terras é reconhecida a propriedade definitiva, devendo o Estado emitir-lhes os títulos respectivos" (BRASIL, 1988).

É possível perceber, pela própria estrutura do artigo, que o mesmo entra em vigência apresentando inúmeras lacunas e inconsistências em torno dos conceitos abordados, tais como "remanescentes", o marco temporal a ser adotado, bem como a ausência de um procedimento para a realização do processo de titulação, haja vista que o artigo propôs a inserção de uma modalidade nova de título de propriedade, em que somente a compra ou a permanência na terra não justificariam a emissão do título para a comunidade quilombola (ARRUTI, 1997).

A inexistência de um procedimento padrão para o processo de titulação resultou na publicação de inúmeras regulamentações, a sua maioria de autoria do INCRA (Instituto Nacional de Colonização e Reforma Agrária), órgão em âmbito federal responsável por este trabalho, as quais tinham por finalidade organizar como as comunidades que estavam acessando a essa prerrogativa seriam atendidas. Após diversas mudanças e indefinições, atualmente encontra-se em vigência o Decreto $n^{\circ} .4887 / 2003$, que regulamenta a titulação de territórios quilombolas.

[...] através do Decreto $n^{\circ} 4.887 / 2003$, definiram-se, para fins de atos demarcatórios dos territórios quilombolas, quem seriam os sujeitos a quem se destinaria tal direito. Nesse documento oficial, conceituam-se como comunidades "remanescentes de quilombos" os grupos étnico raciais que se autoatribuem tais características, devendo possuir uma trajetória histórica própria que estabelece relações territoriais específicas, sobretudo, vinculados a uma ancestralidade negra na qual estão relacionadas formas de resistência à opressão histórica que tais comunidades sofreram (FURTADO, 2012, p. 101). 
De acordo com o decreto, o processo de titulação que inicia com o auto reconhecimento e com a emissão da certificação pela Fundação Cultural Palmares (FCP) e finda com a emissão do título é um caminho longo e tortuoso de ser percorrido. Tais dificuldades esbarram em inúmeros fatores, entre os quais podem ser elencados: 1) a própria definição do procedimento, o qual é complexo e necessita que o processo percorra diversos órgãos até que seja emitido o título; 2) a divisão da malha agrária brasileira, fazendo-se necessário desapropriar terras, fazer um levantamento dos títulos de propriedades e das áreas de competência da União; e 3) o conflito de interesses entre proprietários de terras e a população das comunidades quilombolas, ou até mesmo do Estado em destinar essas terras a essas comunidades (PEREIRA, 2002).

Após mais de vinte anos da publicação do art. 68 do ADCT, somente 174 comunidades quilombolas foram tituladas em todo o Brasil pelo INCRA e 1.695 processos ainda se encontram em tramitação nos órgãos federais e estaduais, conforme pode ser observado na Figura 1:

Figura 1 - Mapa de distribuição das comunidades quilombolas tituladas nos estados brasileiros e os processos em andamento.

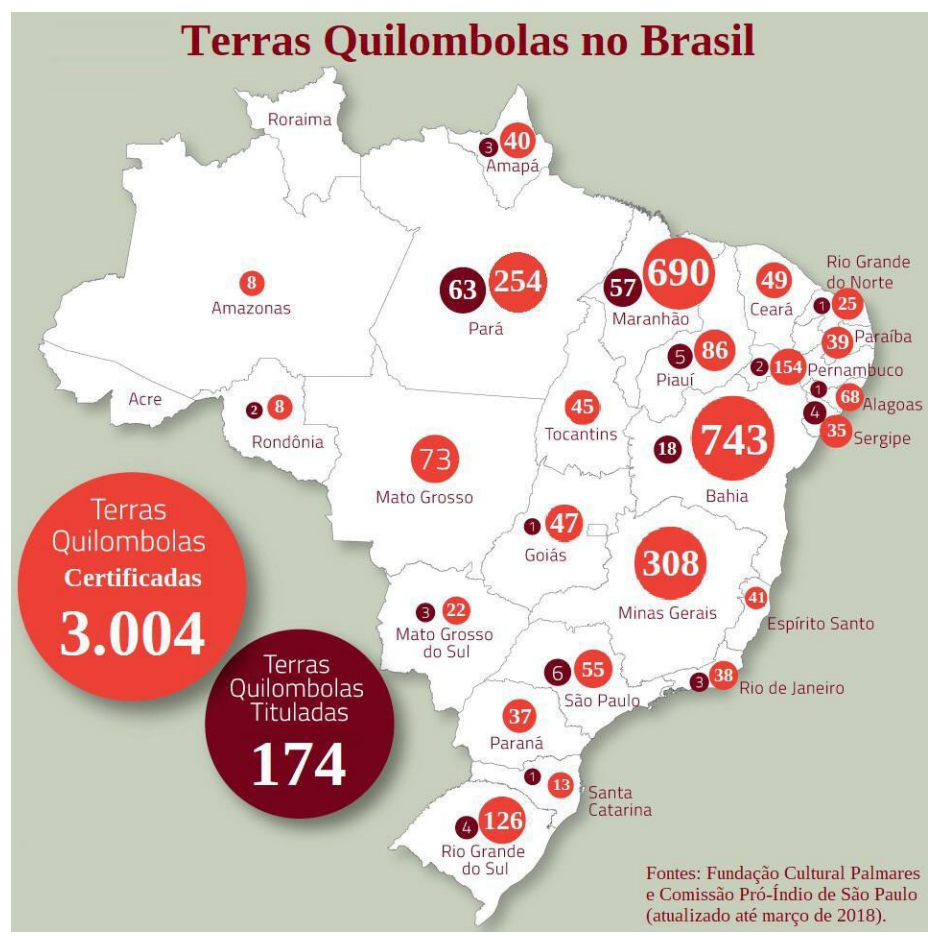

Fonte: Comissão Pró-Índio de São Paulo, 2018. 
Vale ressaltar que, dos territórios titulados, somente $20 \%$ foram realizados por órgãos federais, sendo os demais titulados por órgãos da esfera estadual, em especial, os Institutos de Terras. Nestes órgãos os processos tendem a ser mais céleres, pois tratam de terras devolutas ou até mesmo que se encontram em posse do Estado, não necessitando realizar desapropriações ou verificar a condição da terra em relação a demais órgãos estaduais. Entretanto, esta não é a realidade da maioria das comunidades quilombolas do país, as quais necessitam do INCRA para realizar o processo de titulação e que devido aos inúmeros entraves existentes ao longo do procedimento previsto pelo Decreto $n^{\circ}$. 4887/2003 acabam tramitando de forma mais vagarosa.

Ao se falar do Maranhão, temos um dos estados com maior presença de comunidades quilombolas distribuídas ao longo de todas as suas microrregiões, sendo a Baixada Maranhense a com maior concentração. Outro fator específico do estado e que tem trazido à tona exemplos factuais quanto o atraso nos processos de titulação de terras são os elevados índices de conflitos agrários, o que torna a necessidade de concretização desta demanda ainda mais alarmante, pois resguardar esses territórios implica automaticamente na proteção da vida das pessoas que pertencem a tais territórios.

Segundo a Comissão Pastoral da Terra (CPT), ao longo dos anos os casos de conflitos agrários e ameaças de morte têm aumentado no Maranhão, conforme pode-se observar na Figura 2. 
Figura 2 - Levantamento do número de áreas de conflito e ameaças de morte no Maranhão no período de 2010-2017.

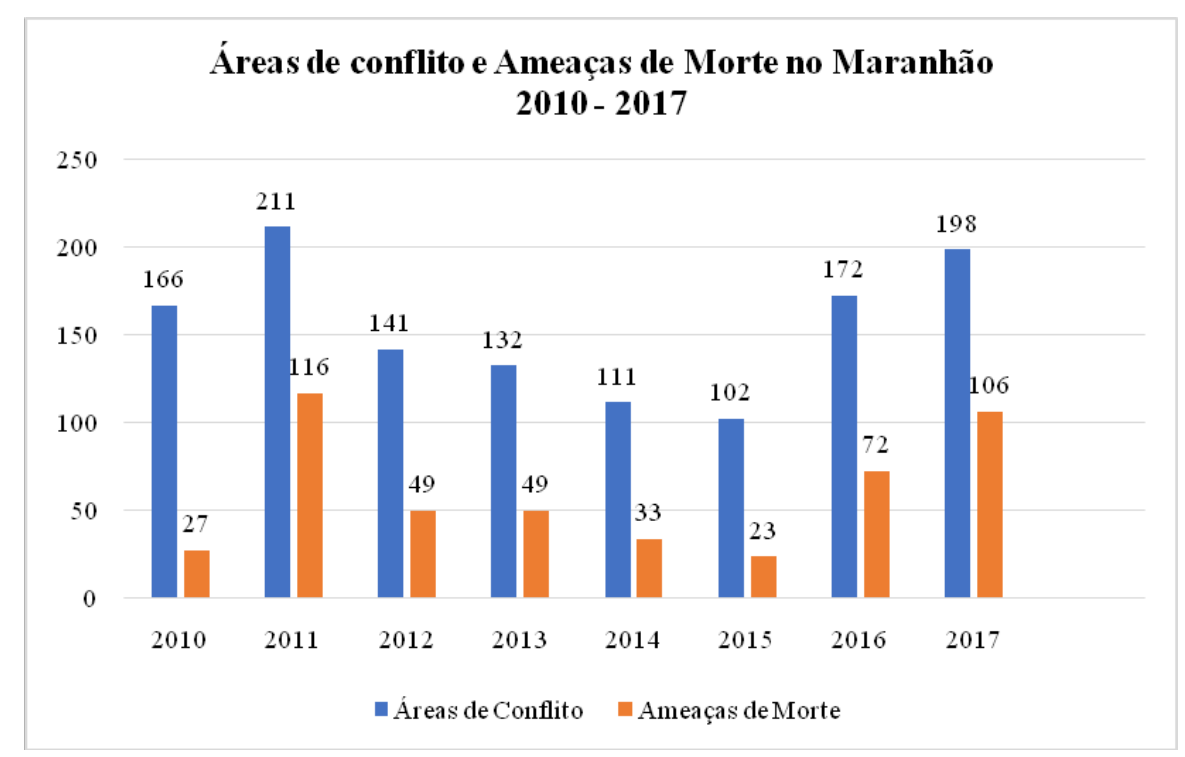

Fonte: Comissão Pastoral da Terra, 2018.

Apesar dos dados serem levantados para abarcar não somente as comunidades quilombolas, mas também as demais populações do campo, como posseiros e indígenas, por exemplo, os números revelam uma realidade histórica no estado e do país: a concentração de terras e a inércia do Estado perante essas questões têm sido um dos principais fatores de assassinatos de camponeses (OLIVEIRA, 2001).

Entretanto, se o acirramento dos conflitos gera morte, gera também formas de luta e pressão frente a ineficiência estatal em garantir a titulação e regularização dos territórios ocupados pelas comunidades quilombolas. É nesse contexto que, no Maranhão, surgem organizações para exigir o cumprimento das garantias constitucionalmente definidas, bem como visibilizar os casos de violência e abuso de poder no interior do estado, em que se faz necessário o entendimento de formas de mobilização e leituras políticas que agenciam os direitos instituídos para comunidades quilombolas a partir da nova Carta Magna.

Incialmente, na década de 1970, o Centro de Cultura Negra do Maranhão (CCN-MA) inicia um trabalho de mapeamento das comunidades quilombolas do estado, por meio do Projeto Vida de Negro 
(PVN). Posteriormente, em 1997, associado o CCN-MA, a ACONE$R \cup Q$ (Associação de Comunidades Negras Rurais Quilombolas) inicia suas atividades atuando enquanto uma organização para representação das comunidades quilombolas do Maranhão. Já em 2011, após denúncias de violência e morte de lideranças quilombolas no estado, o MOQUIBOM (Movimento Quilombola do Maranhão), através de ocupações e acampamentos em frente a órgãos públicos, traz à tona a inobservância do governo estadual e federal em relação a demanda das comunidades quilombolas, bem como a vulnerabilidade delas em relação a violência no campo.

Ao falar em sujeitos de direitos, almeja-se a análise das formas de protagonismo e compreensão dos marcos legais acionados pelos sujeitos, ou seja, o entendimento dos modos e uso destes, levando-se em consideração as contradições desse processo e a complexidade da realidade social. Assim, tendo em vista cobrir o cenário de mobilização das comunidades quilombolas no Maranhão e suas interfaces frente ao Estado e diferentes formas de agenciamento dos direitos instituídos, este trabalho tem por objetivo analisar os processos de emergência de dois segmentos organizados de comunidades quilombolas, a saber, a ACONERUQ e o MOQUIBOM.

Para a sua concretização, realizou-se revisão bibliográfica e documental, tendo em vista perceber ações de organização das comunidades quilombolas, seu protagonismo e leituras políticas, bem como as intervenções do Movimento Negro, em especial do CCN-MA. Houve registro de ações de outras entidades de mediação, como a CPT no meio rural maranhense. Além disso, foi feito trabalho de campo para a percepção de leituras políticas e esquemas de diferenciação entre os segmentos organizados das comunidades quilombolas entre os anos de 2011 e 2015, acompanhando ocupações de órgãos fundiários, como o Instituto Nacional de Colonização e Reforma Agrária (INCRA) e Instituto de Colonização e Terras do Maranhão (ITERMA), pequenas reuniões de organização e deliberação em comunidades rurais, planejamentos e avaliações de atividades e projetos .

Nesse sentido, ganha destaque as proposições de James Scott (2013) ao analisar formas de resistência não explicitas ou declaradas, 
ao mesmo tempo em que chama a atenção para esquemas de mobilização menos evidentes. Assim, privilegiou-se os planos internos dos segmentos organizados, através de acompanhamento de reuniões, atividades de organização e encontros em comunidades quilombolas e participação em atos de protesto, grandes mobilizações e apresentação de demandas a instituições públicas, com destaque para Órgãos Fundiários como os supracitados.

Ao tratar de movimentos e organizações sociais, é necessário perceber os discursos postos em dois planos (interno e externo) em que toma-se como principal estratégia para a análise proposta a "observação situada", a partir da Antropologia Interpretativa, pois, segundo Clifford Geertz (2008), as formas do saber são sempre, e inevitavelmente, locais, inseparáveis de seus instrumentos e invólucros em que para o entendimento das percepções dos agentes políticos das entidades, será necessário para que se torne possível uma "descrição densa".

Nesse sentido, é importante situar as injustiças as quais as comunidades quilombolas estão expostas. Tendo em vista expor os diferentes tipos de desigualdades, tem-se um importante aporte teórico desenvolvido por Nancy Fraser (2006) que esclarece a existência de "coletividades bivalentes", ou seja, tipos sociais que sofrem simultaneamente dois tipos de injustiças diferentes, a saber, econômicas e simbólicas. Estes tipos de injustiças colocam tais coletividades sobre um duplo julgo, já que sofrem ao mesmo tempo com privações de ordem econômica, como pauperização, baixos salários, pouca mobilidade social ascendente, baixo acesso ao mercado de trabalho formal, como também estão expostas a desrespeitos de ordem simbólica, como formas de representação degradantes, estigmas, racismo, machismo e homofobia. Estas formas de injustiça são tratadas pela autora a partir de suas diferenças, em suas matrizes específicas em termos socioeconômicos e simbólicos e enquanto respostas a serem dadas a tais questões, influindo nos caminhos que podem ser adotados pelos movimentos sociais.

Ao abordar esta questão frisa-se que, apesar das desigualdades encontrarem-se entrelaçadas e necessitarem, segundo Fraser, de "remédios simultâneos" que respondam ao desafio de possibilitar 
conquistas socioeconômicas e simbólicas conjuntamente, a forma de tratar com tais constitui-se enquanto um dilema aos movimentos sociais. Situa-se a questão: ao priorizarem-se aspectos puramente econômicos, ou seja, de redistribuição socioeconômica, existe o risco de perder de vista questões relacionadas a ganhos simbólicos, incorrendo-se em possíveis esquemas de homogeneização em termos de classe e renda, com desprezo a especificidades relacionadas ao gênero, questão étnico-racial, de orientação sexual; quando tratadas questões puramente simbólicas, ou seja, de reconhecimento, pode ocorrer o encastelamento dos sujeitos em si mesmos, perdendo assim aspectos mais genéricos e estruturais.

Como forma de ampliar esse debate, cabe situar a posição teórica adotada por Axel Honneth (2003), que aponta ser fundamental a definição de um critério normativo para a análise das situações de conflitos contemporâneos, sendo fundamental a avaliação da "gramática moral" que está por trás dos conflitos. Para ele, lutas por distribuição seriam lutas por reconhecimento de acordos firmados intersubjetivamente, onde o não-reconhecimento é a base do sofrimento analisado contemporaneamente. Nesse sentido, seria importante ir além de critérios que se pautem somente nas demandas dos movimentos sociais e suas expressões mais diretas e visíveis para conseguir obter um olhar geral das formas de sofrimento em uma sociedade capitalista, sendo indispensável perceber diversas expectativas dos cidadãos. Ao abordar tais questões o autor chama a atenção para como os conflitos também giram em torno de proteção legal, em que coletividades específicas almejam ser reconhecidas formalmente.

No trato direto com os sujeitos pesquisados, foram realizadas entrevistas abertas com lideranças da ACONERUQ e MOQUIBOM e o uso de gravador como forma de registro. Optou-se por esse escopo, entendendo as lideranças como sujeitos reconhecidos por deter certa representação política, ao mesmo tempo em que se reconhecem enquanto tal, ou seja, são definidos e se autodefinem enquanto lideranças. Porém, não se silenciou a fala dos demais membros, mantendo a atenção para suas pautas, conhecimentos e interesses ao longo da experiência de campo, como forma de captar vozes dissonantes. 
Dessa forma, para que um evento seja considerado entrevista, "la recolocación de dados debe tener lugar em uma situación cara-a-cara. La formulacion tambien deve producirse em um contexto de investigación e involucrar la formulación de perguntas por parte del investigador" (BRIGGS,1986, p. 5).

\section{CENÁRIOS MULTIFACETADOS DE MOBILIZAÇÃO POLÍTICA: A ACONERUQ E O MOQUIBOM NO MARANHÃO}

A ACONERUQ teve sua criação no ano de 1997, sendo organizada enquanto um "fórum de representação das comunidades quilombolas do Maranhão" (ESTATUTO, 2007). Esta associação, pelo próprio período histórico e vínculos, foi assessorada diretamente por setores do Movimento Negro, como o CCN-MA, entidade fundada em $1979 \mathrm{em}$ São Luís, seja em sua constituição, seja nos primeiros trabalhos desenvolvidos pela entidade. Nesse sentido, as análises do Movimento Negro sobre a realidade das comunidades quilombolas do Maranhão remete a figura de Mundinha Araújo, historiadora e militante, que a partir de sua curiosidade e empenho começa a tentar compreender a situação dessas comunidades ainda na década de 1970, como situa a autora ao historiador Adelmir Fabiani por meio de carta:

Ouvira falar que no interior, isto é, nos centros de alguns municípios existiam lugares onde 'só morava pretos' e que esses pretos não se misturavam com ninguém, ou seja, não havia qualquer vestígio de miscigenação entre eles". Naquele tempo a minha curiosidade como negra em saber mais sobre esses negros da zona rural levou-me a contatar aqui mesmo em São Luís com pessoas dos municípios, viabilizado a possibilidade de servirem de intermediárias quando chegasse até lá e tivesse que deslocar-me para os povoados (FABIANI apud ARAÚJO, 2007).

O trabalho de Mundinha Araújo ocorreu de forma voluntária, realizando visitas a comunidades rurais, a partir de contatos com representantes e lideranças locais, se debruçando sobre os modos de viver e 
fazer existentes nessas comunidades, em seus calendários de festas, práticas socioculturais e memórias do pós-escravidão, entre os anos de 1976 e 1978. Nas primeiras comunidades visitadas, não ocorre a identificação de conflitos fundiários, todavia, como situa a própria Mundinha Araújo, isso não significa que não existissem, pois "dezenas de comunidades já vinham lutando desde os anos 40,50 e 60 contra as invasões de pessoas de fora que resultavam na expulsão dos antigos moradores nas terras conhecida como "dos pretos" (ADELMIR apud ARAÚJO, 2007). Assim, antes mesmo do Movimento Negro assumir a causa das comunidades quilombolas no Maranhão, entre meados dos anos de 1970 e 1980, com a fundação do CCN, estas comunidades já vinham se organizando e tentando resistir contra a invasão de suas terras por parte de grileiros e fazendeiros, como situa Mundinha Araújo ao historiador Adelmir Fabiani:

As comunidades negras rurais Santo Antônio dos Pretos, Bom Jesus dos Pretos, Santa Rosa dos Pretos, Jacareí dos Pretos e outras, vinham se organizando contra a grilagem, antes mesmo de o movimento negro assumir a causa, inclusive "arrecadando recursos entre eles mesmos para pagar honorários de advogados, despesas cartoriais, viagens para a capital e outras" (FABIANI apud ARAÚJO, 2007).

Nesse sentido, é com a criação do CCN em 1979 que ocorre a centralização das demandas das comunidades quilombolas em uma entidade sediada em São Luís, dando destaque às situações de privação, conflitos agrários e as necessidades específicas dessas comunidades. Assim, a partir do conhecimento de Mundinha Araújo, somados às articulações da recém-criada entidade, surge um projeto com o objetivo de cobrir a realidade agrária e as demandas das comunidades quilombolas, intitulado PVN (Projeto Vida de Negro), que vigorou entre 1988 e 2005 em parceria com a SMDH (Sociedade Maranhense de Direitos Humanos). Tal projeto considerava significativamente dados e a produção pioneira de Mundinha Araújo, enquanto uma das fundadoras do Centro, agregando a isso a possibilidade de financiamento e a disponibilidade de pesquisadores e militantes do Movimento Negro em 
trabalhos de campo, pesquisa cartorial e outras tarefas. Desta forma, o projeto visava colocar em prática o artigo 68 do ADCT, bem como registrar modos organizativos e práticas socioculturais existentes nas comunidades quilombolas, buscando o intermédio junto ao poder público tanto em esfera estadual quanto federal nos processos de efetivação de garantias legais, tendo "sido um lugar de reflexão sistemática sobre as mobilizações quilombolas, acoplando o conhecimento militante às memórias locais de resistência" (ALMEIDA, 2002, p. 15).

Tal projeto, contou com o apoio significativo de entidades externas, bem como com recursos oriundos do governo Federal e parcerias com instâncias do Governo Estadual do Maranhão em que "as atividades desenvolvidas junto às comunidades negras pelo PVN tiveram apoio da Fundação Ford (EUA), a Oxfam (Inglaterra), a EZE (agora EED, Alemanha), a Cese (Bahia) e a Fundação Cultural Palmares/Ministério da Cultura" (FABIANI, 2009, p. 11).

\begin{abstract}
Entre pequenos encontros municipais, somados ao empenho das comunidades quilombolas e a assessoria do CCN, surge em 1997 a ACONERUQ. Tal entidade vinha a substituir a Coordenação Estadual Provisória dos Quilombos Maranhenses (CEPQM), criada em 1995 e com o intuito de auxiliar nas demandas das comunidades quilombolas em processo de organização graças aos trabalhos do PVN. Nesse sentido, a criação da ACONERUQ está ligada diretamente as atividades do CCN, nos processos de organização possíveis através do $P V N$, como situa Ivo Fonseca, primeiro coordenador da ACONERUQ, na sede do CCN, em 2013:A montagem da ACONE$R \cup Q$ vai surgindo naturalmente e a gente tinha o Centro de Cultura Negra que dava o foco nos encontros regionais e estaduais. Só para você ver, nós fomos oficializar a entidade no quinto encontro estadual. Teve várias reuniões nos municípios para explicar como era as coisas e aí eles já diziam por que a gente não faz uma organização estadual?!
\end{abstract}

A partir do exposto por Ivo Fonseca, tem-se uma explicação sobre a montagem da ACONERUQ, considerada por ele "natural", surgindo a partir de demandas e assessoria do CCN. Assim, pode-se 
inferir que se teria somado a vontade de criação de uma entidade específica por parte de lideranças quilombolas em um cenário de crescente organização, o interconhecimento das dificuldades partilhadas, através de encontros estaduais e municipais organizados pelo CCN, as limitações institucionais da Coordenação Provisória e a necessidade de abranger as demandas em nível estadual. Como resultado se tem a montagem da entidade ocorrendo após seminários nos municípios de Cururupu, Mirinzal, Alcântara e Turiaçu ao longo do ano 1996 e a realização do V Encontro das Comunidades Negras Rurais no Maranhão. Nesse sentido, as bases estruturais de criação da entidade se encontravam nos municípios de Itapecuru-Mirim, Penalva, Caxias e Codó (PVN, 2005, p. 50). Por sua vez, também se pode perceber que a entidade foi pensada por lideranças como um fórum de representação das comunidades quilombolas que realizasse a interface junto ao Estado, o acesso a políticas públicas e garantias formais. Como pontua Ivo Fonseca, dando continuidade a entrevista ocorrida em 2013, na sede do CCN, e comentando sobre os primeiros trabalhos da ACONERUQ:

O foco principal era trabalhar para que as comunidades conquistem seus territórios e no período que eu fui coordenador eu encaminhei muitos processos para o INCRA e de outro lado que nós trabalhava era a questão da formação política nas comunidades, era a base entender o processo na ACONERUQ, entender a formação. Entender o processo vindo de baixo para cima e não de cima para baixo, então nós tinha essa capilaridade. Outro ponto que nós trabalhava era a questão das normas constitucional. Quando a ACONERUQ começa nós também passamos por isso em nível nacional, porque não adiantava nós estarmos aqui e as portas estarem fechadas quanto a esses ordenamentos. Nós também trabalhamos políticas básicas como educação, saúde, estradas. ${ }^{3}$

3 FONSECA, Ivo. Movimentos Sociais e Poder: um esboço sobre a emergência do Movimento Negro no Maranhão Entrevista concedida à Igor Thiago Silva de Sousa para seu trabalho de conclusão de curso defendido na Universidade Estadual do Maranhão. 2013. 
$\mathrm{Na}$ entrevista com Ivo Fonseca, realizada em uma sala do CCN, este demonstrava satisfação ao frisar que os primeiros trabalhos desenvolvidos pela ACONERUQ durante sua gestão, ao mesmo tempo situava a sintonia da entidade com marcos e questões legislativas nacionais. Assim, enquanto falava, sua entonação mudava ao tratar do compromisso com políticas relacionadas as comunidades quilombolas, demonstrando orgulho e seu empenho na promoção das comunidades quilombolas frente a instituições públicas, dando ênfase ao que foi desenvolvido naquele período, como políticas básicas (educação, saúde e estradas) e encaminhamentos ao INCRA, em que os modos de falar, entonação e ênfases foram significativos no entendimento das explicações dadas (BRIGGS, 1986). Assim, Ivo Fonseca explicitava a necessidade simultânea de diferentes políticas públicas, desde o acesso a titulação dos territórios, passando por políticas assistenciais e de estímulo à produção agrícola e de educação especial para comunidades quilombolas.

Assim, a partir do exposto pode-se perceber que em seu trabalho de representação, a ACONERUQ lida com um enumerado de situações e demandas oriundas das comunidades quilombolas, que envolvem desde políticas de titulação e regularização fundiária que são realizadas por órgãos federais e estaduais, como o INCRA e ITERMA, bem como o acesso a políticas públicas de educação, moradia, infraestrutura, água potável, insumos agrícolas etc. Outro aspecto importante, se refere a necessidade de uma entidade desse tipo, que funcione como um ente formal perante o Estado, capaz de representação, firmamento de contratos, arrecadação de valores e que ao mesmo tempo, mantenha as comunidades organizadas e mobilizadas a partir desse modelo institucional. Em uma conversa com Maria Eunice Machado Aires, a dona Nice, tem-se interessantes questões apontadas. Dona Nice, é oriunda de Penalva, militante da ACONERUQ e uma das fundadoras da entidade, tendo representatividade tanto com comunidades quilombolas quanto entre quebradeiras de coco babaçu organizadas no Movimento Interestadual de Quebradeiras de Coco Babaçu (MIQCB):

A ACONERUQ é a associação quilombola do estado do Maranhão, então essa associação foi criada para representar uma entidade jurídica porque o nosso movimento negro já tem mais 
de 300 anos, tá. Nós que 'vem' do Maranhão, nós 'precisava' de uma entidade jurídica que apresentasse 'nós', né. Porque quando você vai para uma luta, vai para qualquer trabalho, eles precisam que a gente apresente um documento lá pela entidade e 'nós' era só movimento, hoje nós somos entidade porque tem um documento que apresenta 'nós' juridicamente como entidade. Então, ela foi criada através disso aí, para representar 'nós' em todo lugar do estado do Maranhão, os quilombolas. ${ }^{4}$

A entrevista com dona Nice se deu em um encontro interno da ACONERUQ, em que a liderança se mostrou a vontade e interessada em explicar o que Ihe era solicitado, ao que tempo que complementava e corrigia dados, sendo uma das responsáveis por "quebrar o gelo" naquela ocasião. Assim, a partir desta, percebe-se a importância conferida as formalidades por parte dos quilombolas que fundam a ACONERUQ, nos termos da capacidade de representação jurídica perante o Estado e frente a outros segmentos sociais. Para ela, já não se trataria apenas de um movimento social justamente por essa capacidade, pela possibilidade de "representação" e apresentação de "documentos". Assim, a ACONERUQ funciona como uma entidade formal e autônoma das comunidades quilombolas, capaz de assegurar certa visibilidade e institucionalidade seja frente a antagonistas, seja para com possíveis parceiros, tendo tanto projetos junto com financiadores externos, como a União Europeia (UE), como articulações junto ao governo do Estado do Maranhão. Tal representação ocorre a partir da filiação das associações de moradores dessas comunidades à entidade, o pagamento de taxas de anuidade e a possibilidade de formação de chapas que concorrem eleitoralmente a gestão por determinado período (ESTATUTO, 2007).

Quanto ao outro segmento organizado, temos que o MOQUIBOM ganha destaque a partir de ocupações a órgãos públicos e passeatas que passam a ocorrer a partir de 2011, com denúncias públicas sobre assassinatos de lideranças quilombolas no campo. Nesse sen-

4 AIRES, Maria Eunice Machado. Entrevista concedida à Igor Thiago Silva de Sousa. 2015 Entrevista compõem a dissertação de mestrado intitulada: Processos de mobilização quilombola: a ACONERUQ e o MOQUIBOM no Maranhão 
tido, o surgimento do movimento está relacionado aos trabalhos da CPT junto a comunidades quilombolas no interior do Maranhão, mais especificamente na região da Baixada Maranhense, local em que o movimento nasce inicialmente. Esses trabalhos se dão, sobretudo, ao visibilizar as garantias Constitucionais existentes, bem como no auxílio às comunidades nos processos de auto identificação e elaboração de relatos sintéticos a serem enviados a FCP, como forma de assegurar a obtenção do certificado emitido pela Fundação. Assim, as ações do MOQUIBOM giram em torno de pequenos encontros que ocorrem nas comunidades quilombolas, pequenas ações em nível local na organização dessas comunidades, bem como em encontros maiores, que ocorriam com a troca de experiências e vivências, a partir da construção de laços e da demonstração de pertenças étnicas em comum e situações de opressão compartilhadas por esses sujeitos.

Reunidos a partir da mística da terra como dom de Deus e direito de todos que dela precisam, o primeiro encontro da articulação MOQUIBOM aconteceu no sítio dos "padres" em Mangabeira, povoado de Santa Helena. Embalados e motivados por cânticos que denunciam o descaso do poder público e a necessidade de luta dos despossuídos, essa articulação marcou o primeiro semestre de 2011 com mobilizações jamais vistas, sobretudo por se tratar de um movimento quilombola (FURTADO, 2012, p. 260-261).

Parte desses encontros aconteciam também em instalações ligadas à Igreja Católica, como o mencionado "sítio dos padres" no município de Mangabeiras, reunindo comunidades quilombolas, padres, estudantes universitários e setores próximos a CPT e alguns sindicatos. Nesse sentido, as ações da CPT se davam principalmente pela interlocução que a entidade confessional tem para com as comunidades rurais, pelo prestígio gozado pelos padres e pela atuação destes na mediação de conflitos e na resolução de questões pontuais. Assim, a CPT também funciona como um foco de mediação entre as comunidades quilombolas e o Estado, ao passo em que ocorrem conflitos fundiários. Parte dessa mediação também se dá por outras entidades ligadas a Igreja Católica, situando esta instituição e as entidades a ela 
vinculadas como importantes atores sociais no campo. Como situa Alfredo Wagner Berno de Almeida:

Ao se disporem como exercendo uma mediação dos antagonismos na área rural e, em decorrência, funcionando como interlocutores obrigatórios frente ao Estado, as instituições religiosas pressionam a estrutura agrária como forças sociais organizadas, deslocando politicamente outros mediadores externos porventura existentes. Ao eclodirem quaisquer conflitos de terra, que envolvam camponeses, grupos indígenas e latifundiários, eles passariam a ser tratados necessariamente pela intermediação desses dois centros de poder: Estado e Igreja (ALMEIDA, 2014, p. 70).

Essas ações de mediação de conflitos no campo, de um lado dão lugar de destaque a Igreja, seja frente ao Estado, seja para com as comunidades rurais que passam a procurar suas entidades para a resolução de questões. Nesse sentido, é a partir desse lugar de mediação privilegiado que ocorre o incentivo para a criação de um novo segmento organizado das comunidades quilombolas, como é o caso do movimento supracitado. Assim, o MOQUIBOM reivindica a rubrica de movimento social por conta de sua não institucionalidade, ou seja, ausência de sede fixa, CNPJ (Cadastro Nacional de Pessoa Jurídica), ou qualquer formalidade além de seus membros agremiados e seu poder de mobilização junto as comunidades, realizando ocupações a órgãos públicos, passeatas e greves de fome, como forma de visibilizar a luta de comunidades quilombolas por direitos territoriais.

Como dado interessante tem-se a relação entre a CPT e o MOQUIBOM. Para vários integrantes do MOQUIBOM, a entidade seria uma mãe, responsável por cuidados, por ter gerado um "filho" a partir de si, de quem é responsável, tendo zelo e cuidado por tal. Dessa forma, mais do que um auxiliar, uma parceira esporádica, a CPT se apresenta como principal entidade de apoio às ações do MOQUIBOM e com ele tendo uma relação estreita, que por vezes se confunde, na medida em que cede parte de suas instalações, orçamento e quadros no auxílio deste movimento. Na ocasião de reunião de quilombolas e agentes da CPT para deliberações sobre as ações do MOQUIBOM, em Catarino 
Borges, o Santinho, em entrevista ocorrida na sede da CPT em São Luís, em 2015, comentava sobre como percebe as relações travadas entre a entidade confessional e o movimento:

A relação da CPT e do movimento é uma relação 100\% mesmo, é $100 \%$ porque na verdade a gente considera nós que somos da coordenação da frente do movimento, nós consideramos a CPT como mãe do MOQUIBOM, porque na verdade ele teve no ventre, botou para fora, é igual menino na barriga de uma mãe, botou para fora, sentou, engatinhou e tá começando a andar, mas sempre ao lado da CPT. A CPT foi nossa mãe e a mãe nunca abandona o filho, até hoje, espero que de amanhã em diante não abandone também, que é um parceiro, uma mãe que criou.

De fala rápida e com um léxico que exige atenção com o que é dito, a liderança quilombola explica como percebe a relação entre CPT e MOQUIBOM. Para ele, tem-se a entidade confessional como uma "mãe", dados os apoios e cuidados estabelecidos. Nesse sentido, o horizonte entre delegação e mediação parece caminhar numa linha tênue, em que "membros das instituições confessionais empreenderam o risco calculado de agir ou de falar em nome de camponeses ou de grupos indígenas, como se a delegação consistisse numa etapa necessária para alcançarem uma existência coletiva e, portanto, de direitos políticos que configuram a plenitude da cidadania (ALMEIDA apud BOURDIEU, 1990, p. 192). Já para Almirandir Costa, liderança do MOQUIBOM, em reunião de comunidades quilombolas vinculadas ao MOQUIBOM no "sítio dos padres" em 2015, o surgimento do movimento e as motivações para tal são os seguintes:

Nós não tinha (sic) representantes, pois como o atual governo diz, os representantes dos negros é a ACONERUQ, então, não se tinha representação nenhuma de um movimento social, uma representação nossa. Já tinha a conversa de criação de um movimento com o pessoal da CPT e nós (se) reunia e com isso a gente foi conversando com as comunidades, achamos que tinha a necessidade de nos representar mesmo, por isso fundamos 
O MOQUIBOM porque é ele a representação das comunidades quilombolas do Maranhão. ${ }^{5}$

A partir do exposto pela liderança, pode-se perceber que algumas comunidades quilombolas não se sentiam representadas a partir da ACONERUQ. Porém, a mesma entidade detém de prestígio perante o governo, sendo vista como a representante das comunidades quilombolas do Maranhão, mesmo com certa insatisfação destas e a consequente eclosão de um novo segmento organizado a partir de articulações com a CPT. Desta forma, percebe-se o papel de mediação da CPT entre setores rurais no Maranhão, funcionando assim como um mobilizador das demandas apresentadas pelas comunidades quilombolas no Maranhão.

Assim, críticas referentes a ausência de uma representação capaz de abarcar as diferentes regiões e situações vivenciadas por estas comunidades fizeram eclodir, em 2011, o MOQUIBOM, responsável por também organizar as comunidades enquanto segmento organizado à parte da ACONERUQ. Como críticas, as comunidades que iniciaram o processo de criação do MOQUIBOM alegavam estarem descobertas, sem atenção e trabalhos sendo desenvolvidos em seus municípios e localidades, sem saber como agir ou garantir seus direitos. Reclamavam, entre outras coisas, de desconhecimento e falta de formação para defender seus modos de vida e conhecimentos sobre os trâmites formais no processo de titulação territorial.

Como ressalva sobre a relação entre os quilombolas organizados no MOQUIBOM e a CPT, se parece ter tons de dependência e não se estar livre de contradições, na medida em que os quilombolas parecem estar estreitamente vinculados a formalidade assegurada pela entidade confessional, seus contatos com entidades de apoio e a assessoria de profissionais liberais a ela ligados. A CPT abre um leque de possibilidades em termos de divulgação e exposição de situações em meios eletrônicos ou impressos, como os Cadernos de Campo da

5 COSTA, Almirandir. Entrevista concedida à Igor Thiago Silva de Sousa. 2015 Entrevista compõem a dissertação de mestrado intitulada: Processos de mobilização quilombola: a ACONERUQ e o MOQUIBOM no Maranhão 
entidade, a assessoria e mobilização de agentes pastorais, o uso de espaços ligados à Igreja Católica, a transferência de prestígio, o auxílio de advogados e outros profissionais, bem como a notoriedade e carisma que a entidade tem entre alguns setores sociais.

Por outro lado, pelo próprio prestígio gozado, as entidades confessionais tem a possibilidade de mobilizar e politizar, a partir de novas matrizes discursivas, os setores a ela vinculados. É assim que, a partir de um "trabalho de repensar" suas ações, a CPT passa a dar destaque a categoria quilombo em contraposição a categoria de posseiro nas atividades da entidade. Esse repensar reflete tanto o reconhecimento de categorias e legislação específicas para o trato com a questão quilombola de maneira mais abrangente, como o entendimento da generalidade desta questão em si tratando do estado do Maranhão, isto a partir de sua própria inserção e atividades no meio rural. A partir do trabalho de campo ao longo dos anos, manteve-se a interlocução constante com Fábio Silva, ex-agente pastoral da CPT da cidade de Pinheiro e que teve destaque nas ações desta entidade na Baixada Maranhense. Com Fabio Silva, se teve a possibilidade de realizar viagens para o interior do estado, ter longas conversas, acompanhar discussões e ocupações do MOQUIBOM. Assim, ele situa em termos precisos sobre o repensar categorial da CPT.

A CPT Pinheiro, da qual eu faço parte, sempre teve um trabaIho ligado as comunidades tradicionais, ribeirinhos, quebradeiras de coco, posseiros e até que a gente foi conhecendo essa discussão das comunidades quilombolas, a questão da legislação e tudo e muitas das comunidades que a gente trabalhava com a categoria de posseiros, né, de posseiras, de posseiros, de comunidades quebradeiras de coco, são também comunidades quilombolas. Começamos o trabalho, eu sempre coloco a parte com mais força a partir de 2010 , um trabalho mais forte no município de Serrano e essas comunidades que a gente já conhecia na baixada, com esse trabalho, foi despertando o conhecimento de outras, também a gente foi levando essa informação sobre as comunidades quilombolas, os direitos que elas tinham, os direitos que elas tem e a gente sentiu que essas comunidades tavam, elas não tinham visibilidade nas suas 
lutas. Elas tavam lutando de forma isolada, cada comunidade lutando, resistindo, para manter os seus territórios, umas perderam, outras conseguiram manter em parte, outras conseguiram seu território, mas cada comunidade vinha lutando de forma muito separada, sem unir. Não existia aquele sentimento de um povo, de um povo quilombola. Existiam as lutas que vem desde a década de 1960, 1970, então essas lutas inclusive já existiam, então onde elas aparecem no caderno de conflitos da CPT de 2010 e 2011, aonde o caderno de conflitos da CPT dá um salto, dá um salto e o Maranhão desponta como o estado com maior número de conflitos. Mas não era que não existia os conflitos, os conflitos já existiam, estavam lá, não era publicizado, não tinha visibilidade de luta. Então, eu acredito que a grande sacada aí do trabalho da CPT foi juntar essas comunidades, né; colocá-las num encontro e começar a deixar eles se encontrarem e ver que os problemas eram comuns, né, o foro, a questão do impedimento de fazer uma casa, impedimento de buscar seus extrativismos do qual eles utilizavam, então esse, eu acho essa grande sacada de juntá-los e eles verem que o problema era comum e os unia pelas mesmas razões, então eu acho que isso foi um passo importante, a partir daí, das comunidades se encontrarem e começar a pensar que era necessário pensar uma lutar que desse direito aos territórios. ${ }^{6}$

Fábio Silva, que tem experiência no trato com comunidades quilombolas e esteve acompanhando diretamente as atividades do MOQUIBOM desde 2011 até 2016, pontua com precisão o momento em que a CPT passa a reconhecer a realidade de comunidades rurais do interior do Maranhão como a de comunidades quilombolas. Nesse sentido, a partir de sua fala pode-se perceber a importância das ações da CPT no surgimento do MOQUIBOM. Como primeiro ponto, temos um repensar categorial à luz da própria realidade maranhense, que coloca sob suspeição o conceito de posseiro, historicamente utilizado pela CPT e Igreja Católica no trato de conflitos fundiários, e traz à tona formas de uso e pertenças étnicas que remetem a especificidade de

6 SILVA, Fábio. Entrevista concedida à Igor Thiago Silva de Sousa. 2015 Entrevista compõem a dissertação de mestrado intitulada: Processos de mobilização quilombola: a ACONERUQ e o MOQUIBOM no Maranhão 
parte significativa da população das comunidades rurais no Maranhão, dando vazão ao conceito comunidades quilombolas para o atendimento a esta realidade e aos conflitos fundiários nelas existentes. Como segundo ponto, temos que a partir dos trabalhos da CPT há maior organização das lutas que já existiam por parte das comunidades quilombolas, agora munidas de certo referencial, apoiadas pela entidade confessional e reconhecendo que sua realidade era também compartilhada por outras comunidades em situação semelhante.

Assim, situações de pagamento de foro, típica forma de arrendamento da terra, pago através de produtos em espécie, como com farinha ou arroz; situações de impedimento de construção de casas por parte de supostos proprietários para com as comunidades e outras situações de privação, passam a ser politizadas pela CPT como exemplos de formas de opressão vivenciadas pelas comunidades quilombolas. Outro dado, refere-se à visibilidade dada as lutas dessas comunidades, bem como a situações de conflitos fundiários que a CPT passa a expor sistematicamente a partir de suas publicações anuais, como os Cadernos de Conflitos no Campo, especialmente nos anos de 2011, 2012 e 2013. Assim, tem-se um processo de organização das comunidades ocorrendo a partir das ações da CPT, criando um sentimento de "povo quilombola", como comentado por Fábio Silva.

Como uma questão instigante, se tem as possíveis motivações que podem ter gerado a criação de um novo segmento de organização das comunidades quilombolas, para além da ACONERUQ. Como um primeiro entendimento, temos que o surgimento deste movimento social ocorre pela ausência de atividades da própria ACONERUQ em certas regiões e municípios do Maranhão. Em conversas travadas ao longo do trabalho de campo, Maria José Palhano, antiga coordenadora da ACONERUQ, se mostrava interessada em explicitar as possíveis "lacunas" da entidade que possibilitaram a emergência do MOQUIBOM. Em uma dessas conversas, realizada em 2015 na sede da entidade, ela pontuava que:

Eu vejo a criação do MOQUIBOM como uma forma dos quilombolas que não estavam sendo assistidos e que a ACONERUQ 
tava deixando uma lacuna grande, se organizarem, se reorganizarem. E o que eu acredito, eu creio de verdade, que é bom. Não é ruim. Eu só acho que a gente não pode e nem deve se separar, acho que a gente deve andar juntos, juntar as forças porque quando a gente se junta a gente é forte. Quando a gente se separa a gente enfraquece. Quando cada um toca para um lado, não dá pra fazer um amontoado, porque se dividiu, eu comparo isso com dois elos da corrente, um elo sozinho ele não faz nada, ele é muito frágil, mas quando você junta dezenas, centenas de elo, você tem uma corrente. Aí ela é forte.?

A partir da fala exposta pode-se ter em vista que a "lacuna" na representação das comunidades quilombolas do Maranhão é explicada pela situação em que a entidade se encontrava, sendo assunto espinhoso durante o trabalho de campo. Assim, esse assunto mostrou-se de difícil trato, uma vez que exigia a exposição de questões internas da ACONERUQ, que giram em torno das prestações de contas, processos judiciais, uso dos recursos obtidos através de convênios com o governo federal e estadual e eleições de chapas para coordenação da entidade, o que fugia aos limites de confiança e a possibilidade de exposição dos sujeitos pesquisados. Nesse sentido, parte da discussão sobre ética nas pesquisas antropológicas tem girado em torno do

consentimento (formal ou informal) do grupo investigado, o tipo de informação que o pesquisado deve obter da pesquisa de que participa, a capacidade legal e intelectual dos entrevistados de entender a pesquisa proposta e as formas de coerção que podem estar envolvidas nessa relação (DEBERT, 2004, p.45).

Assim, o intuito da pesquisa não era expor a uma situação vexatória a ação de antigas lideranças e membros da ACONERUQ ou mesmo trazer à tona dificuldades na gestão dos recursos gerenciados pela entidade de forma desrespeitosa. Portanto, houve um cuidado calculado com "os riscos envolvidos na publicação dos resultados, porque

7 PALHANO, Maria José. Entrevista concedida à Igor Thiago Silva de Sousa. 2015 Entrevista compõem a dissertação de mestrado intitulada: Processos de mobilização quilombola: a ACONERUQ e o MOQUIBOM no Maranhão 
nossas conclusões não podem constranger, humilhar ou trazer prejuízos para as populações estudadas" (DEBERT, 2004). Por outro lado, como forma de diferenciar sua gestão das anteriores responsáveis por, genericamente, colocar a ACONERUQ em situação de "abandono" e "descrédito", Maria José Palhano, mesmo com certas ressalvas e limites, expunha sua opinião quanto a situação da ACONERUQ, não se privando de sempre que se sentindo invadida, solicitar que o gravador fosse desligado, pois "isso não pode ficar gravado", conforme comentava ao entrar em assuntos de difícil explicação, conforme situa:

Eu acredito que com relação a ACONERUQ tava uma coisa muito debilitada porque apesar de dizermos que a ACONERUQ tava aqui, em defesa dos territórios quilombolas, em defesa da comunidade quilombola, naquele momento ela não tava em defesa nem dela mesmo. ${ }^{8}$

Maria José Palhano continuava a comentar sobre o início de suas atividades como coordenadora, quando passou a compor a gestão da entidade como parte de uma "junta governativa" dada a situação de débitos para com funcionários e o imóvel que servia de sede para a entidade, este tendo inclusive sido alvo de ordem judicial de despejo. Ao mesmo tempo em que remetia ao passado da ACONERUQ com tristeza e pesar nas palavras, também tinha cuidado com o que era dito, não se privando de evitar temas e terminar conversas entre sorrisos e mudanças estratégicas de assunto, como comenta Maria José Palhano:

Quando eu cheguei na ACONERUQ, eu costumo dizer que a ACONERUQ estava num estado bem precário, ela não tava nem mesmo mais sendo convidada para nada porque a forma como deixaram ela, deixaram ela de uma forma muito decadente, eu posso dizer assim, porque quando eu cheguei na ACONERUQ era um estado total de abandono, não tinha acontecido eleição, e eu vim para uma junta governativa enquanto já como presidente da junta, e para organizar a eleição porque

$8 \quad$ Idem 5. 
não tinha acontecido a eleição segundo os antigos por falta de recursos, e ao chegar eu realmente constatei que era isso que tinha acontecido, porque uma semana depois que eu cheguei, chegou uma ordem de despejo, eram muitos débitos, aluguéis atrasados, funcionários atrasados, era muita coisa que tava pendente. Mas aí, depois de organizar o processo eu soube que eu também poderia me candidatar, aí eu me candidatei e ganhamos a eleição, uma eleição muito cheia de conflitos, porque tinha interesses particulares por trás das pessoas que não queriam que acontecesse eleição mas aconteceu, né. $E$ a gente ficou como coordenadora geral, então eu fui ai para frente de julho de 2010 lutar para ver se tirava, se resgatava pelo menos a credibilidade política da instituição. ${ }^{9}$

Assim, conforme o entendimento de Maria José, o que possibilitou a emergência de outro segmento organizado foi a situação difícil em que se encontrava a entidade, bem como as lacunas deixadas na representação de algumas comunidades quilombolas no Maranhão. Por outro lado, o entendimento de pessoas pertencentes ao MOQUIBOM, o seu surgimento não está ligado propriamente a ausência de atuação da ACONERUQ em certas regiões, a sua inexistência em certos municípios ou comunidades, mas pelo tipo de ações empreendidas pela entidade. Nesse sentido, O MOQUIBOM traria à tona formas de luta, instrumentos de mobilização e exposição das situações vivenciadas pelas comunidades quilombolas que estariam além dos limites da institucionalidade proposta pela ACONERUQ. Em conversa privada na sede da CPT, Catarino dos Santos Borges, o Santinho, membro do MOQUIBOM me explicava que:

A gente não atua naquele local que a ACONERUQ atua menos, mas sim em todas as regiões que a ACONERUQ atuava e tá atuando, nós também 'tamo' atuando. Até mesmo porque o movimento surgiu pela necessidade, da ausência da ACONE$R \cup Q$ não só em dois, três pontos, mas sim nos quatro pontos do Maranhão, porque é uma entidade que é pra representar as comunidades tradicionais, principalmente as quilombolas. É para

$9 \quad$ Idem 5. 
fazer a representatividade dessa questão. Então, o MOQUIBOM atua em todos os motes que a ACONERUQ atuava e tá atuando. Eu não tenho a ACONERUQ e o MOQUIBOM como uma divergência, entre aspas também, né, na verdade hoje a ACONERUQ era para tá com a gente, porque quando nós entramos, no início, chamamos eles para vir com nós. Então, eles achava que, não sei se é verdade ou não, mas eles conversam que nós éramos uns doidos, com a questão do INCRA, para fazer as mobilizações, sem ter decisões nenhum e sem ter capacidade de fazer o que nós fizemos. Pois nós mostramos para eles que nós éramos pequenininhos, hoje 'tamo' grande, 'tamo' com articulações maiores, né, éramos pequenininhos mas fazemos a linha de grande. Então, essa linha de grande hoje surgiu em nível nacional. Então, o medo deles hoje é porque eles tiveram conhecimento que nós não éramos na verdade o que eles pensavam. Eles pensavam que na verdade, com certeza a CPT só ia botar nós na frente e deixar nós ir embora, caminhar, mas do início até hoje a CPT é nossa mãe e jamais vai abandonar nós. ${ }^{10}$

A partir desse comentário de Catarino Borges, pode-se situar uma das primeiras ocupações públicas realizadas pelo MOQUIBOM no ano de 2011. Esta ocupação realizada na superintendência do INCRA-MA gerou certa situação de animosidade e farpas entre os dois segmentos de organização quilombola. De um lado, o MOQUIBOM se apresentava com um setor radical, realizando uma das primeiras greves de fome em ocupações quilombolas que se ouvira falar no Maranhão, junto a protestos públicos e caminhadas, denunciado assassinatos no campo e a impunidade no caso do assassinato de Flaviano Pinto Neto, liderança da comunidade quilombola de Charco, município de São Vicente Férrer, alvejado por tiros em 30 de outubro de 2010. Por outro lado, a ACONERUQ aparecia como a entidade que gozava de credibilidade frente o Estado e instituições públicas, mas sem qualquer controle ou possibilidade de intervenção na ocupação realizada, sem autoridade sobre os quilombolas acampados, como se mostrou recorrente nas

10 BORGES, Catarino dos Santos. Entrevista concedida à Igor Thiago Silva de Sousa. 2015. Entrevista compõem a dissertação de mestrado intitulada: Processos de mobilização quilombola: a ACONERUQ e o MOQUIBOM no Maranhão 
ocupações que se sucederam em anos posteriores, como 2012, 2013, 2014, 2015, 2016, $2018^{11}$.

Outro aspecto pontuado, segundo Naildo Braga, liderança do MOQUIBOM, e que se tornou figura central na ocupação do INCRA/MA em 2015, seria o destaque dado aos processos de titulação dos territórios quilombolas por parte do movimento. Esse seria a principal pauta do movimento em suas ocupações e demais ações. Em reunião coletiva realizada na sede da CPT da cidade de Pinheiro, pôde-se ter a oportunidade de realizar uma conversa simultânea com 5 lideranças quilombolas, elas se mostravam interessadas em registrar seus próprios entendimentos, expor idas a encontros, pequenos feitos em ocupações e os afazeres do movimento em tom descontraído e leve. Nesse sentido, para os quilombolas situados no MOQUIBOM, a centralidade na exigência das titulações territoriais seria um diferencial quanto a ACONERUQ. Conforme Naildo Braga, em entrevista na sede da CPT de Pinheiro em 2015:

O MOQUIBOM surgiu e atua principalmente em defesa da titulação dos territórios para as comunidades quilombolas. Porque foi uma necessidade que se alastra aí por muito tempo a questão da titulação das terras das comunidades quilombolas e que até então as instituições que existiam, os movimentos que existiam, nesse sentido, não tavam correspondendo à altura das demandas e também das necessidades que essas comunidades enfrentam. Então foi daí que surgiu o MOQUIBOM e daí que ele atua principalmente nessa linha, de titulação das áreas das comunidades quilombolas. ${ }^{12}$

A partir do exposto pode-se perceber que há a apontamento quanto a certa rivalidade entre segmentos que organizam as comunidades quilombolas no Maranhão, existindo disputas, ou algum

11 Para situar de forma detalhada algumas das ocupações do MOQUIBOM, consultar SOUSA (2013); SOUSA (2016), FURTADO (2012).

12 BRAGA, Naildo. Entrevista concedida à Igor Thiago Silva de Sousa. 2015 Entrevista compõem a dissertação de mestrado intitulada: Processos de mobilização quilombola: a ACONERUQ e o MOQUIBOM no Maranhão 
desconforto quanto a menção ou co-presença. Este desconforto também se reflete quanto a divisão de espaços públicos, como mesas e eventos oficiais e desentendimentos nas leituras das ações empreendidas e formas de compreensão do cenário político por ambos. Assim, esse fator se mostrou um adicional nas pesquisas realizadas, na medida em que o caminhar em campo, a tentativa de estabelecimento de laços que vislumbrassem o acesso simultâneo a informações e projetos relativos ao MOQUIBOM e a ACONERUQ era como "pisar em ovos", que em vários momentos, o campo mais pareceria um "campo minado", dadas desconfianças e cobranças por parte dos sujeitos com os quais se pesquisava. Porém, o mesmo campo cheio de minas, se mostrou um espaço de reflexão sobre o métier antropológico, na medida em que mais do que produzir literalizações, ou mesmo esquemas de tipificação social, o nosso ofício tem sido desafiado em uma produção que busque devolver as pessoas com as quais aprendemos à sua cotidianidade, ao seu lugar comum e simples, devendo-se perceber que

[...] parte de nossa tarefa consiste em descobrir por que aquilo que as pessoas que estudamos fazem e dizem parecem-lhes, eu não diria evidente, mas coerente, conveniente, razoável. Mas a outra parte consiste em estar sempre se interrogando sobre até que ponto somos capazes de seguir o que elas dizem e fazem, até que ponto somos capazes de suportar a palavra nativa (GOLDMAN, 2006, p. 167).

Assim, quanto as ações das comunidades quilombolas e sua interface direta com as instituições estatais, o cenário caminha para a não resolução de conflitos agrários e a não titulação dos territórios quilombolas, pois apesar das formas de ação destas comunidades ser variada quanto as estratégias, se dando seja pela via institucional, seja pela ação propriamente de mobilização política, não há avanços quanto ao número de comunidades tituladas no Maranhão, tendo-se nenhuma titulação realizada pelo INCRA, que conta com um enumerado de processos parados na instituição, trazendo a tona sua ineficiência em cumprir os acordos firmados. 
O que se percebe é o adiamento de problemas por parte do Estado brasileiro no que tange a titulação territorial, dando-se passos curtos ou inexistentes. Por outro lado, e talvez por isso mesmo, tem-se a dinamização das formas de agenciamento dos direitos conquistados desde 1988 por parte das comunidades quilombolas, contando-se com estratégias e leituras políticas que variam entre certa margem institucional e a tentativa de ação a partir desse eixo como expresso pela ACONERUQ, já o MOQUIBOM tem investido em formas de ação que tem na mobilização direta sua linha de ação, com a exposição e a divulgação dos conflitos fundiários no interior do Maranhão e a pressão através de ocupações enquanto estratégia de interlocução para com as instituições responsáveis. Porém, apesar desse reinventar nas ações e da potência das demandas das comunidades quilombolas no Maranhão, há o agravamento de situações que envolvem casos de homicídios e ameaças a lideranças quilombolas em que as instituições estatais têm se mostrado ineficientes e entregando as comunidades aos seus próprios esforços e fé.

\section{CONSIDERAÇÕES FINAIS}

O presente artigo buscou analisar as diferentes facetas de organização das comunidades quilombolas no Maranhão. Para isso, expôs de forma genérica o processo de formação de seus segmentos organizados, através da ACONERUQ, e do posterior surgimento do MOQUIBOM. Ressaltou as relações com entidades de mediação como o CCN-MA e a CPT e chamou atenção também para as diferentes estratégias e leituras políticas em termos de (im)possibilidades de ação.

\section{REFERÊNCIAS}

ALMEIDA, Alfredo Wagner Berno de. Terras de preto no Maranhão: quebrando o mito do isolamento. São Luis: ECN / SMDH / PVN, v.1, 2002.

ALMEIDA, Alfredo Wagner Berno de. Agionarmento Agônico: a trajetória de instituições religiosas como mediadoras de conflitos 
agrários na Amazônia. In: LACERDA, Paula Mendes (Org). Mobilização social na Amazônia: a luta por justiça e educação. Rio de Janeiro: E-papers, 2014.

ARRUTI, José Maurício A. P. A emergência dos 'Remanescentes': notas para o diálogo entre indígenas e quilombolas. MANA, v. 3, n. 2, p. 7-38, out.1997.

BOURDIEU, Pierre. Coisas ditas. São Paulo: Editora Brasiliense, 1990.

BRASIL. Constituição da República Federativa do Brasil. Brasília, 1988.

BRIGGS, Charles. Aprendiendo cómo preguntar: uma evalución sociolinguística de la entrevista enlainvestigación em las ciências sociales. Cambridge: Cambridge University Press, 1986.

BRITTO, Carlos Ayres. Teoria da constituição. Rio de Janeiro: Forense, 2003.

COMISSÃO PASTORAL DA TERRA. Cadernos de Conflitos no Campo - Brasil. Goiânia/São Paulo: CPT-Loyola, 2010 - 2017.

COMISSÃO PRÓ-ÍNDIO. Observatório terras quilombolas. Disponível em: $<$ http://cpisp.org.br/direitosquilombolas/observatorio-terras-quilombolas/>. Acesso em: 17 out. 2018.

DEBERT, Guita Grin. Ética e as novas perspectivas da pesquisa antropológica. In: Antropologia e ética: o debate atual no Brasil. Niterói: EdUFF, 2004.

ESTATUTO DE REFORMULAÇÃO DA ACONERUQ (Associação das Comunidades Negras Rurais), 2007.

FABIANI, Adelmir. O quilombo antigo e o quilombo contemporâneo: verdades e construções. XXIV Simpósio Nacional de História. São Leopoldo: Anais, 2007. 
FABIANI, Adelmir. Os quilombos contemporâneos maranhenses e a luta pela terra. Estudios Historicos, N², 2009.

FRASER, Nancy e HONNETH, Axel. Redistribution or Recognition? A political-philo sophical exchange. London/ New York: Verso, 2003.

FRASER, Nancy. Da redistribuição ao reconhecimento? Dilemas da justiça numa era pós-socialista. In: Cadernos de Campo, São Paulo, n. 14/15, p. 232-239, 2006.

FERREIRA, Emanuel de Melo. A evolução da solidariedade: das sociedades clássicas à principiologia constitucional. In: Anais do XIX Congresso Nacional do CONPEDI, Florianópolis/SC: Fundação Boiteux, 2010, p. 5985-5993.

FURTADO, Marivânia Leonor Souza. Aquilombamento no Maranhão: um Rio Grande de (im)possibilidades. 2012. 313 f. Tese (Doutorado em Geografia) - Programa de Pós-Graduação em geografia, Universidade Estadual Paulista, Faculdade de Ciências e Tecnologia, Presidente Prudente, 2012.

GEERTZ, Clifford. A interpretação das culturas. Rio de Janeiro: LTC, 2008.

GOLDMAN, Marcio. Alteridade e experiência: antropologia e teoria etnográfica. In Etnográfica, Volume. X (1), 2006.

LEITE, Ilka Boaventura. O legado do testamento: a comunidade de casca em perícia. Porto Alegre: Editora da UFRGS; Florianópolis: NUER/UFSC, 2004.

OLIVEIRA, Ariovaldo Umbelino de. A longa marcha do campesinato brasileiro: movimentos sociais, conflitos e Reforma Agrária. In: Estudos avançados, v. 15, n. 43, p. 185-206. 2001.

OLIVEIRA Jr., Adolfo Neves de. Reflexão antropológica e prática pericial. In: CARVALHO, José Jorge de. (Org.). O quilombo do Rio das Rãs: histórias, tradições, lutas. Salvador: EDUFBA, 1995. 
PEREIRA, Deborah Macedo Duprat de Brito. Breves Considerações sobre o Decreto No 3.912/01. In: Quilombos - identidade étnica e territorialidade. O'DWYER, Eliane Cantorino (Org.). Rio de Janeiro: Fundação FGV, 2002.

PROJETO VIDA DE NEGRO. Vida de negro no Maranhão: uma experiência de luta, organização e resistência nos territórios quilombolas. Coleção Negro Cosme, v. 4. São Luís: SMDH, CNN-MA, PVN, 2005.

SARMENTO, Daniel. O reconhecimento do direito à terra dos quilombolas a partir do multiculturalismo dos direitos humanos. Disponível em: <http://www.mpf.mp.br/atuacao-tematica/ccr6/documentose-publicacoes/artigos/docs_artigos/o-reconhecimento-do-direito-a-terrados-quilombolas-a-partir-do-multiculturalismo-dos-direitos-humanos/ view>. Acesso em: 30 set. 2016.

SCOTT, James C. A dominação e a arte de resistência: discursos ocultos. Portugal: Letra Livre, 2013.

SOUSA, Igor Thiago Silva de. Movimentos sociais e poder: um esboço sobre a emergência do movimento negro no Maranhão. $65 \mathrm{f}$. Trabalho de conclusão de curso (Graduação em Ciências Sociais) Curso de Ciências Sociais, Universidade Estadual do Maranhão, SãoLuís, Maranhão, 2013.

SOUSA, Igor Thiago Silva de. Processos de mobilização quilombola: a ACONERUQ e o MOQUIBOM no Maranhão. 2016. 132 f. Dissertação (Mestrado em Antropologia Social) - Universidade Federal de Santa Catarina, Programa de Pós-Graduação em Antropologia Social, Faculdade de Ciências Humanas, Florianópolis, 2016.

SOUZA, Bárbara Oliveira. Aquilombar-se: um panorama histórico, identitário e político do Movimento Quilombola Brasileiro. 2008. 204 f. Dissertação (Mestrado em Antropologia Social) - Programa de Pós-Graduação em Antropologia Social, Universidade de Brasília, Brasília. 2008. 
SUNFELD et al. $\mathrm{O}$ direito à terra das comunidades quilombolas. [s.n.]: Sociedade Brasileira de Direito Público (SBDP), 2002.

\section{ENTREVISTAS}

BRAGA, Naildo. Entrevista concedida à Igor Thiago Silva de Sousa. 2015 Entrevista compõem a dissertação de mestrado intitulada: Processos de mobilização quilombola: a ACONERUQ e o MOQUIBOM no Maranhão

BORGES, Catarino dos Santos. Entrevista concedida à Igor Thiago Silva de Sousa. 2015 Entrevista compõem a dissertação de mestrado intitulada: Processos de mobilização quilombola: a ACONERUQ e o MOQUIBOM no Maranhão

COSTA, Almirandir. Entrevista concedida à Igor Thiago Silva de Sousa. 2015 Entrevista compõem a dissertação de mestrado intitulada: Processos de mobilização quilombola: a ACONERUQ e o MOQUIBOM no Maranhão

FONSECA, Ivo. Movimentos Sociais e Poder: um esboço sobre a emergência do Movimento Negro no Maranhão Entrevista concedida à Igor Thiago Silva de Sousa para seu trabalho de conclusão de curso defendido na Universidade Estadual do Maranhão. 2013.

AIRES, Maria Nice Machado. Entrevista concedida à Igor Thiago Silva de Sousa. 2015 Entrevista compõem a dissertação de mestrado intitulada: Processos de mobilização quilombola: a ACONERUQ e o MOQUIBOM no Maranhão.

PALHANO, Maria José. Entrevista concedida à Igor Thiago Silva de Sousa. 2015 Entrevista compõem a dissertação de mestrado intitulada: Processos de mobilização quilombola: a ACONERUQ e o MOQUIBOM no Maranhão

SILVA, Fábio. Entrevista concedida à Igor Thiago Silva de Sousa. 2015 Entrevista compõem a dissertação de mestrado intitulada: Processos de mobilização quilombola: a ACONERUQ e o MOQUIBOM no Maranhão 